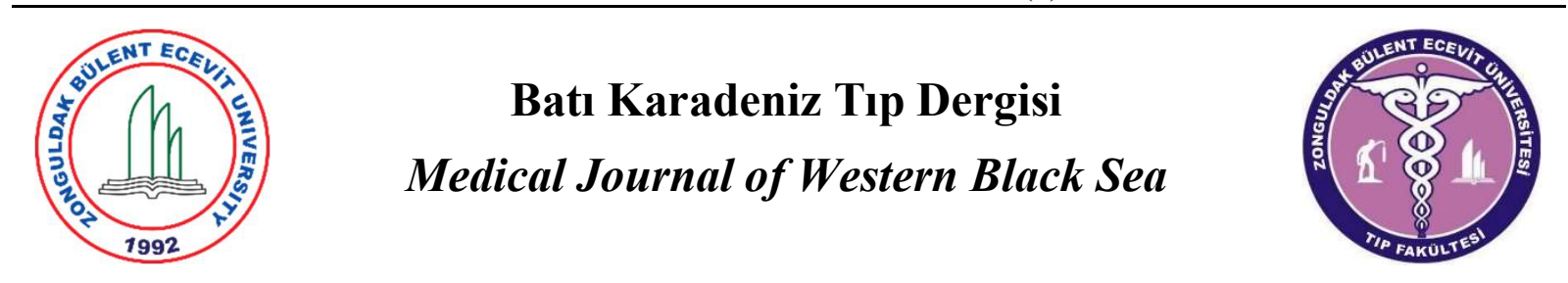

Olgu Sunumu

Doi: $10.29058 / \mathrm{mjwbs} .2018 .3 .1$

\title{
Phlegmasia Cerulea Dolensi Bir Olguda Farmakomekanik Trombektomi
}

\section{Uygulamas 1}

\section{Sitk1 Akın Turan ${ }^{\text {a }}$}

${ }^{a}$ Kalp Damar Cerrahisi Anabilim Dalı, Bülent Ecevit Üniversitesi, Zonguldak, Türkiye.

ORCID : Sitkı Akın Turan 0000-0001-9565-2764

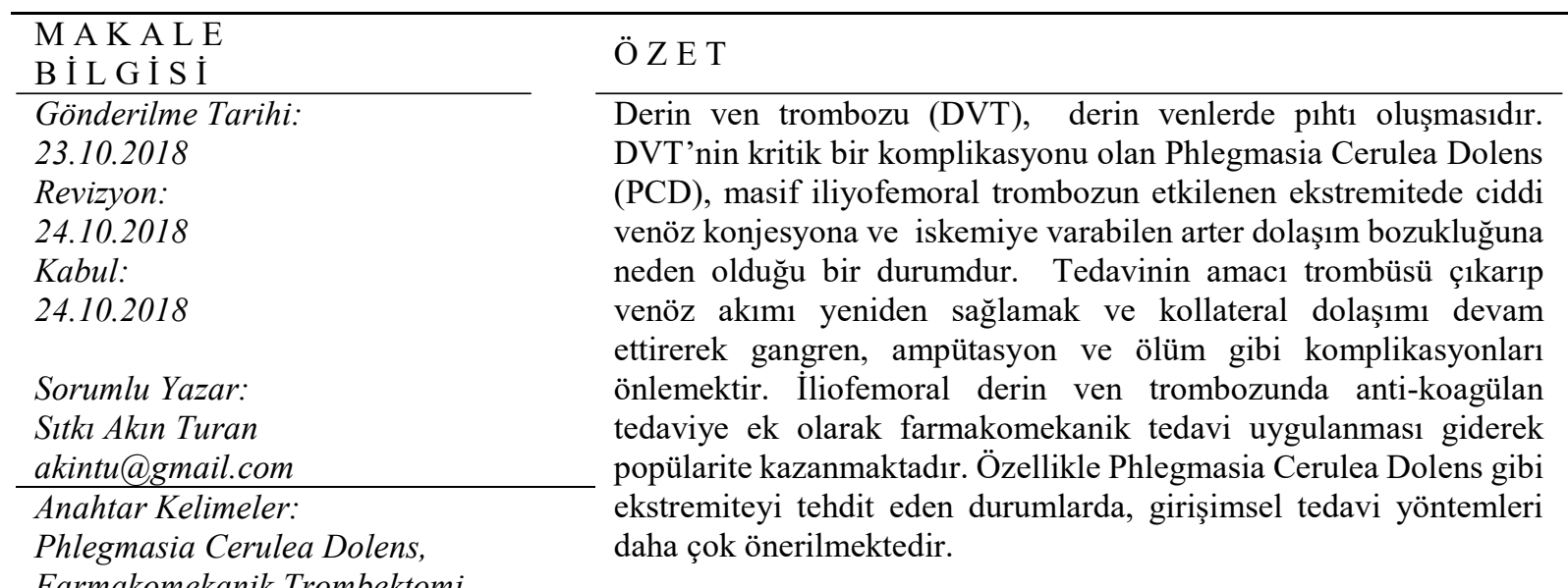

Farmakomekanik Trombektomi,

Trombolitik tedavi, Akut Derin

Ven Trombozu 


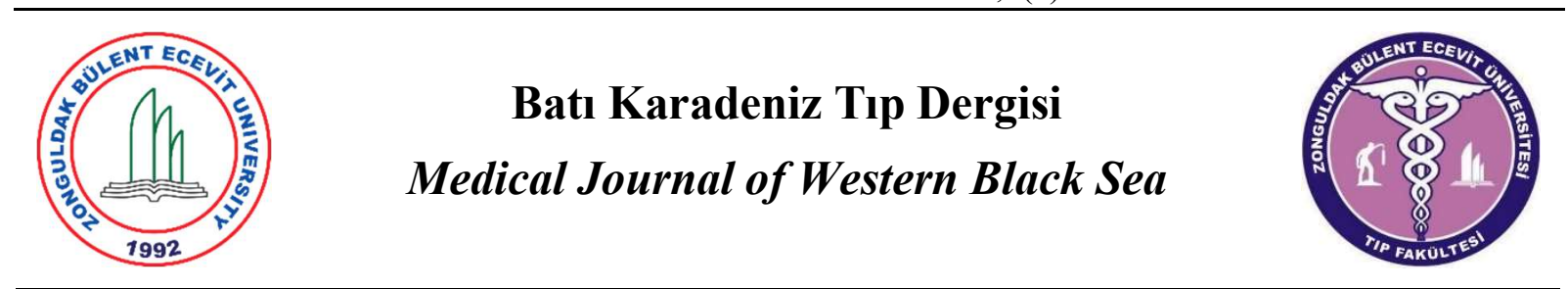

Case Report

Doi: $10.29058 /$ mjwbs.2018.3.1

\title{
The Pharmacomechanical Thrombectomi Treatment In A Patient Having Phlegmasia Cerulea Dolens
}

\author{
Sirkı Akın Turan a,
}

a Department of Cardiovascular Surgery, Bulent Ecevit University Faculty of Medicine, Zonguldak, Turkey.

\begin{tabular}{l} 
A R T I C L E \\
I N F O R M A T I O N \\
\hline Date of Submission \\
23.10 .2018 \\
Revision: \\
24.10 .2018 \\
Accepted: \\
24.10 .2018 \\
\\
Correspondence Author: \\
Sitkl Akın Turan \\
akintu@gmail.com \\
\hline Key Words: \\
Phlegmasia Cerulea Dolens, \\
Pharmacomechanical \\
Thrombectomi, Thrombolytic \\
therapy, Acute Deep Vein \\
Thrombosis
\end{tabular}

\begin{abstract}
A B S T R A C T
Deep venous thrombosis (DVT) is the formation of a blood clot within a deep vein. Phlegmasia cerulea dolens (PCD); a critical complication of DVT, is a condition caused by massive iliofemoral thrombosis that produces severe venous congestion and obstruction of arterial flow; eventually, causing ischemia in the affected extremity. The treatment goals of PCD are to restore venous outflow by removing thrombus burden and maintain collateral circulation to prevent complications such as gangrene, amputation and death. Applications of pharmacomechanic thrombectomi in the iliofemoral acute deep venous thrombosis in addition to the anti-coagulant terapy has gained popularity. Invasive approachs are more recommended for especially limb-threating conditions such as phlegmasia cerulea dolens.
\end{abstract}


Derin ven trombozunun en ciddi komplikasyonları phlegmasia alba dolens (PAD), phlegmasia cerulea dolens (PCD) ve gangrendir. PCD altıncı ve yedinci dekatlarda daha sık görülür ve insidansı kadınlarda daha yüksektir. S1klıkla alt ekstremitelerde görülüp üst ekstremitelerde görülme sıklığı \%5'ten azdır. Sol taraf tutulumu 3-4 kat daha fazadır $(1,2)$. Tetikleyici mekanizma olarak en sik malignansiye (\%20-40) rastlanır. Diğer nedenler arasında genetik yatkınlık, cerrahi öyküsü, travma gebelik, kontraseptif kulanımı yer almaktadır (3).

DVT ve PCD tedavisinde anti-koagülan tedaviye ek olarak trombolitik ve/veya mekanik trombektomi, ve venöz balon anjiyoplasti son yıllarda daha s1k ve daha yaygın kullanılmaktadır (4). Farmakomekanik tedavi özellikle akut iliofemoral derin ven trombozu olan, fonksiyonel kapasitesi yüksek, kanama riski düşük olgularda tercih edilmekte olup girişimsel tedavi yöntemlerine olan ilgi PCD gibi ekstremiteyi ciddi düzeyde tehdit eden olgularda günden güne artmaktadır.

\section{Olgu Sunumu}

Olgumuz 55 yaşındaki bir erkek hasta, sol alt ekstremitede ağrı ve şişlik yakınması ile acil servise başvuran diyabetik erkek hastanın sol alt ekstremitesi uyluğa dek ileri derecede şiş ve siyanotikdi (Resim 1).

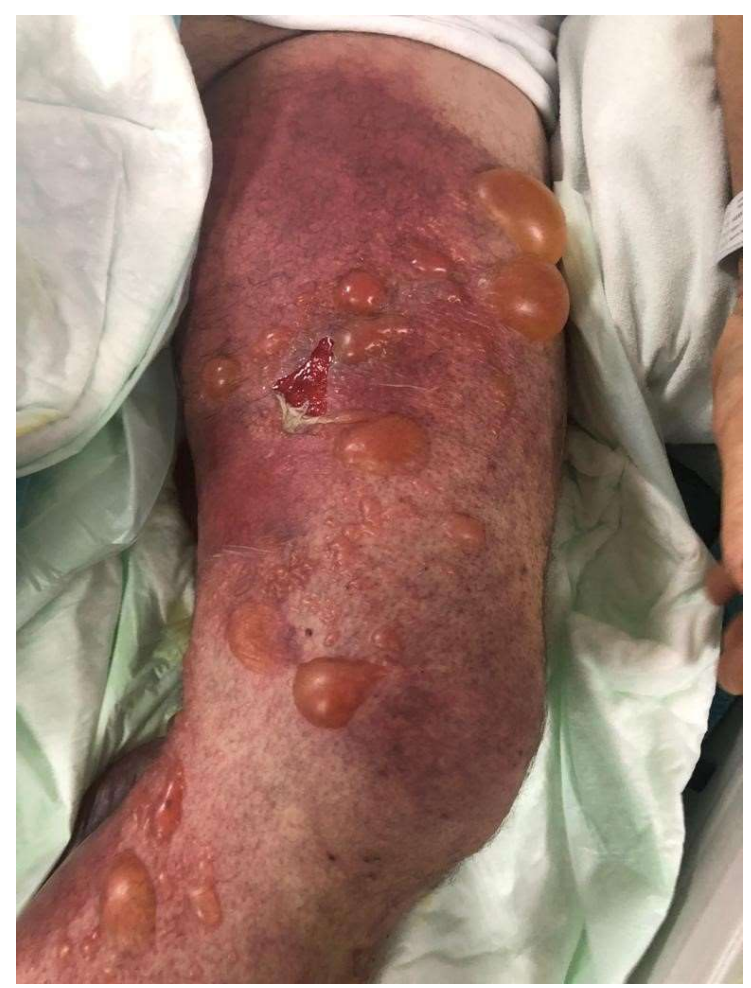

Resim 1. Tedavi öncesindeki görünüm.
Belirgin 1sı artışı vardı. Venöz doplerde iliak seviye ve distalinde akut trombüs ve arteriyel doplerde distalde monofazik zayıf akım saptand.. Arteryel dolaşım halen zayıf da olsa devam ettiği için bacakta soğuma olmamış, hatta konjesyon sonrasında 1s1 artışı ve beyaz küre yüksekliği başlamıştı. Phlegmasia Cerulea Dolens tanısı ile servise kabul edilip unfraksiyone heparin infizyonu ve intravenöz hidrasyon başlandı. İdrar çıkışı olmadığı için nefroloji bölümüce takibe alındı ve düzenli diyaliz planlandı. Isı artışı ve beyaz küre yüksekliği nedeniyle enfeksiyon hastalıkları bölümünce değerlendirildi ve gerekli antibiyotik tedavisi düzenlendi. Medikal tedavisi düzenlenen hastada klinik düzelme olmaması ve ağrısının devam etmesi nedeniyle farmakomekanik tedavi planlandi. Anjiyografi ünitesinde önce karşı femoral venden girilerek renal venlerin altında kalacak şekilde İVK'ya geçici filtre yerleştirildi. Ardından sol popliteal venden girilerek skopi eşliğinde tıkalı iliak seviyede farmakomekanik tromboliz ve aspirasyon uygulandı. Rezidü kalan stenotik bölgeye venöz balon anjiyoplasti uygulandı. Venografide yeterli açıklık sağlandığı gözlendi (Resim 2).

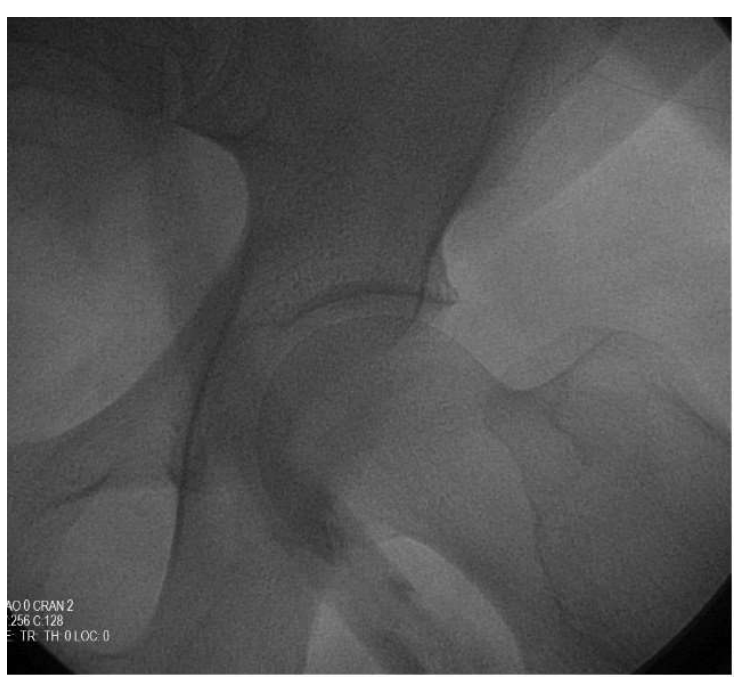

Resim 2. Farmakomekanik trombektomi ve balon anjiyoplasti sonrası venografi.

İşlem sonrasında unfraksiyone heparin infizyonuna, diyalize ve yara bakımı uygulamasına yoğun bakım ünitesinde devam edildi. Geçici İVK filtresi trombektomi sonrasında ilk gün çekildi. Ağrısı geçip bacak şişliği azalmaya başlayınca tedaviye serviste devam edildi. Uyluk seviyesi çapı diğer bacak seviyesine indi ve bacak görünümü normale dönmeye başladı (Resim 3). 


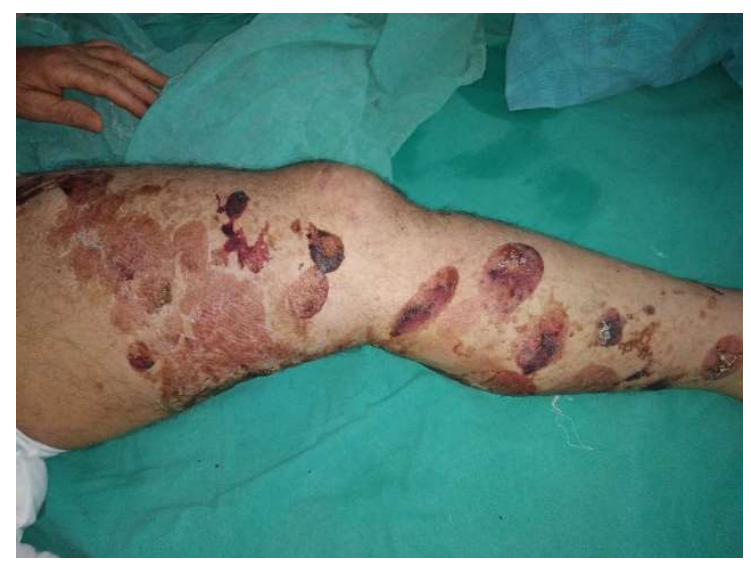

Resim 3. Farmakomekanik tedavi sonrasında medikal tedavinin 4. günündeki görünüm.

\section{Tartışma}

Phlegmasia Cerulea Dolens (PCD), ekstremitede, yüzeyel ve derin venlerin trombozunun nadir ama yüksek mortalite ve morbiditeye neden olabilen sonuçlarından biridir (5). Ani ve şiddetli ekstremite ağrısı ile başlayıp şişme, siyanoz, kompartman sendromu, venöz gangren ve arteriyel dolaşım bozukluğu sonucu iskemiye neden olabilir. Ekstremitedeki siv1 sekestrasyonu sonucu kas, cilt altı ve ciltte dejeneratif değişiklikler ve sistemik olarak kollaps ve hipovolemik şok gelişebilir. En sık nedeni malignite olup diğer nedenler arasında immobilizasyon, hiperkoagülabilite, geçirilmiş DVT, travma ve kontrasepfif ilaçlar yer almaktadır (6). Tanıda ultrasonografi ve venografi yardımcidır. Tedavi seçenekleri arasında heparinizasyon, katater aracilı tromboliz, mekanik trombektomi, anjiyoplasti ve stentleme yer almaktadır. Sonuçları arasında gangren (\%40-60), ampütasyon (\%25-50) ve ölüm $(\% 30)$ sayılabilir $(3,7)$.

\section{Kaynaklar}

1. Bergqvist D, Jendtek S, Lohansen L, Person U, Odegaard K. Cost of Lond-term Complications of Deep Venous Thrombosis of the Lower Extremities: An analysis of a Defined Patient Population in Sweden;Ann Intern Med. 1997;126(6):454-7.

2. White RH. The epidemiology of venous thromboembolism. Circulation. 2003;107(2):14-8.

3. Goldhab SZ. Venous thromboembolism: Epidemiology and magnitude of the problem. Best Practise \& Research Clinical Haematology. 2002;25(2):235-42.
4. Wedantham S, Padington C. Percutaneous option for acute deep vein thrombosis. Semin Intervent Radiol 2005;22(3):195-203.

5. Klok FA, Huisman MV. Seeking optimal treatment for phlegmasia cerlea dolens. Thromb Res 2013;131(4):372-3.

6. Kalagher SD, Kane DD. Phlegmasia cerulea dolens: before and after lysis. Intern Emrg Med 2015;10(1):103-4.

7. Chinsakchai K, Ten Duis K, Moll FL, de Borst GJ. Trends in management of phlegmasia cerulea dolens. Vasc Endovascular Surg 2011;45(1):5-14. 